\title{
Field-testing olfactory ability to understand human olfactory ecology
}

Short Title: Olfactory ability in the field

Kara C. Hoover, Department of Anthropology, University of Alaska, Fairbanks, USA. email: kchoover@alaska.edu

Botescu, Denisa, Department of Anthropology, University College of London, London WC1H OBW.

Piotr Fedurek, Centre for Research in Evolutionary, Social and Inter-Disciplinary Anthropology, University of Roehampton, London SW15 4JD U.K. email: fedurekp@ roehampton.ac.uk

Sophie Aarts, Centre for Research in Evolutionary, Social and Inter-Disciplinary Anthropology, University of Roehampton, London SW15 4JD U.K.

J. Colette Berbesque, Centre for Research in Evolutionary, Social and Inter-Disciplinary Anthropology, University of Roehampton, London SW15 4JD U.K. email: colette.Berbesque@roehampton.ac.uk

Correspondence to be sent to: Kara C. Hoover, Department of Anthropology, University of Alaska, Fairbanks, USA. email: kchoover@alaska.edu 


\begin{abstract}
We know little about human olfactory ability in natural settings — including natural and built environments. Our knowledge derives from clinics and lab experiments using samples of convenience, often students and usually 'WEIRD' populations. Yet, humans live in odor rich environments, most are not western, and many are not industrialized or formally educated. There are currently no methods available for studying olfactory ability outside the lab. Such methods would expand representativeness in datasets and enable a true characterization of human olfactory ability. To explore what clinical methods might be transferrable from the lab to the field, we completed two repeated measures experiments - one in the field and one in the labusing the five-item odor identification test. We report two major findings. First, there are no sufficient methods for mobile field-testing of olfactory ability. Our test of five-item odor identification test was not sufficient in the field due to subjective biases in data analysis and potential for participant odor learning. Second, environment may not a significant factor in olfactory ability when testing occurs in dynamic odorscapes, but food-rich odors may enhance olfactory ability in females. In fact, even in our less than perfect field setting and problematic test tool, females still outperformed males. We discuss the evolutionary and ecological implications of superior female olfactory ability that may have been under selective pressure from foraging activity in our lineage long before the split with our closest relatives, chimps and bonobos.
\end{abstract}

\title{
KEYWORDS
}

Smelling in the wild, sex differences in olfactory ability, odor identification, food odors 


\section{INTRODUCTION}

The vast majority of our knowledge on human olfaction derives from lab studies conducted in odor-controlled environments using samples of convenience, typically white educated industrialized rich and democratic or WEIRD populations (Henrich et al. 2010) — often students (Hanel and Vione 2016). Meanwhile, the vast majority of human olfactory experience is in dynamic non-western and non-industrialized odorscapes. The limited research done on olfactory ability in different ecological settings suggests that non-industrial populations may have superior olfactory sensitivity but not discrimination abilities (Sorokowska et al. 2014; Sorokowska et al. 2013). While these studies provide an intriguing peak at what natural human variation in olfactory ability might be like, comparing data collected in the field to those in the lab challenges interpretation given the unknown variables in the field influencing test outcomes. Thus, we know little about how humans detect, discriminate, and identify odors in mixtures in natural settingsfor humans, natural settings include the built environment, both urban and rural.

Lab data provide insights into smelling odor mixtures. First, while we may detect many to most odors in a complex odor mixture, the whole of that information is not transduced to the brain due to the inhibition of some olfactory receptor cells via receptor competition (Jinks and Laing 1999). Even if all odors in the mix are subliminally processed in the cerebrum, only some are perceived (Hummel et al. 2013). Second, there may be an upper limited to the number of odors detectable individually from mixes - one experiment suggested that more than 30 equal-intensity odorants are perceived as an 'olfactory white' (Weiss et al. 2012). Third, the ability to detect single odors in mixtures may be improved by experience (Sinding et al. 2015) and training (Barkat et al. 2012; Morquecho-Campos et al. 2019). Fourth, there may be ecological pressures that have acted on the filtering mechanisms of the olfactory system. There is a neuronal pattern that suggests we are particularly tuned to food odors (Saraiva et al. 2019). Thus, the olfactory system is limited by its ability to integrate complex whole mixtures into perception and driven by attention to specific compounds. Perhaps environmental variation outside the lab is not a disruptive confounding factor. By widening data collection to field-based settings, a representative sample would be possible and allow us to understand the extent of natural human variation in olfactory ability.

The principle challenge in generating ecologically salient data is the lack of field-based methods (Kern et al. 2014). The only field-validated method is the Olfactory Function Field Exam (OFEE), an 11-minute olfactory function test that uses a modified and abbreviated version of Sniffin' Sticks - two odors for threshold detection (Kern et al. 2014) and five odors for identification (Mueller and Renner 2006). As part of The National Social Life, Health, and Aging Project in the United States, the OFFE was validated on a cohort of 2,304 older adults and conducted in participants' homes following a short odor training session. Results were nearly identical to testing conducted in labs on a similarly aged cohort but not using repeated measures on the same subjects (Kern et al. 2014). OFFE validation results suggest that between-subjects environmental variation was not significant. Olfactory adaptation down-regulates receptor stimulation when odors are constant, however, which means that OFFE subjects were not smelling their home environments and the effect from variation would be small (Auffarth 2013; Dalton 2000). 
Our goal was to assess the impact on olfactory ability from a dynamic environment to which subjects were not adapted. We needed a tool that was highly portable and easy to administer in the field. The ease of administering the two most accurate tests, threshold and discrimination, in the field without a table was prohibitive. That left odor identification. There are three validated short tests of olfactory ability that rely solely on odor identification-a five odor Sniffin' Sticks test (Mueller and Renner 2006), a three odor Sniffin' Sticks test (Hummel et al. 2010), and a three-odor test using microencapsulation (Jackman and Doty 2005). We used the five-item test in two repeated measures studies: a field study comparing olfactory ability in a low odor environment to 1) a polluted environment and 2) a high odor environment; a lab study comparing olfactory ability in a low odor control lab to a high odor experiment condition.

\section{Materials}

\section{MATERIALS AND METHODS}

Our five-item test included four of the original five-item test odors: peppermint, orange, rose, fish (Mueller and Renner 2006). Leather was replaced by garlic because it had a lower identification rate in the UK (Neumann et al. 2012). The field study was conducted in August 2018 and the lab study in February 2019. Materials were purchased in July 2018 and stored at the University of Roehampton at a temperature within the recommended manufacturer's range.

\section{Screening and Testing Protocols}

Testers wore cotton gloves during testing and wore no scented products. Each odor was moved across the nostrils slowly for three seconds. Participants were asked to describe the odor via free response then choose one of 22 terms from a verbal prompt card: five odor terms (one correct per odor), 15 distractor odor terms (none correct for any odor), 'undefinable', and 'no odor' (see Table 2 of Mueller and Renner 2006). The field study consisted of three tests per participant and the lab study consisted of two. Between-test gaps were small (25-30 minutes for field, 15-20 for lab).

\section{Data Coding and Statistical Analysis}

All data were analyzed and graphics plotted in R for Windows v3.6.1 (Charif and Lobry 2007) using the R Studio GUI v1.2.1335 (RStudio Team 2015). Responses were coded as correct, near miss (a related item like lime for orange), far miss (a more general term like citrus for orange), and incorrect (an unrelated item like raspberry for orange) following Cain (1979). Betweencoder agreement (JCB, KCH) was tested by Cohen's kappa ( $)$ using irr (Gamer et al. 2012) in the lpsolve package (Berkelaar 2015). The total correct provided an ordinal level variable describing olfactory ability (Mueller and Renner 2006):

- Poor (0): severely impaired or no sense of smell

- Indeterminate (1 to 3 ): further testing required

- Normal (4-5 correct): normal or slightly reduced sense of smell

The effect on olfactory ability from differing environments was estimated using ordinal regression (AKA logistic regression and cumulative link models), specifically, we used the clmm function in the ordinal package (Christensen 2019). Logistic regression offers a powerful alternative to traditional ordinal tests (Mann-Whitney U, Wilcoxon signed rank sums, Kruskal Wallis) because it allows the estimation of fixed effects on the dependent variable and estimation of repeated measures via a random term (McCullagh 1980) - an ordinal version of mixed-model 
linear regression or repeated measures ANOVA. We used the proportional odds model which assesses the probability of being in $x$ ranked category or lower versus being in any higher ranked category with olfactory rank as the thresholds between categories. We included additional fixed effects - sex because females perform better in lab studies (Oliveira-Pinto et al. 2014; Sorokowski et al. 2019) and age because olfactory ability declines after age 50 in lab studies (Martinez et al. 2017; Sinding et al. 2014). The field study had two additional effects, day and time of testing, due to potential temporal variation in test environments. The proportional odds effects plots were generated in the R package effects (Fox and Hong 2009) using output from the polr function in MASS (Venables and Ripley 2002).

\section{Ethical Considerations}

Field research for this project was approved by the University of Roehampton Ethics Committee, approval number LSC 17/ 213 (JCB, KCH). Written informed consent included asked volunteers to provide no further information beyond a name (signed and printed). Data collection sheets were labelled with a unique numeric ID. The unique numeric ID was not noted on the informed consent which means no personally identifying information was linked to test data. The data collection sheet included basic demographic information (sex, age, ethnicity) and free and verbal prompt responses to each of five odors per location.

\section{RESULTS \\ Coding}

The initial coding of descriptive data by two observers ( $\mathrm{JCB}, \mathrm{KCH})$ was in moderate agreement: Repeat Markets, (free response $\kappa=0.537$, verbal prompt $\kappa=0.500$ ) and Repeat Labs (free response $\kappa=0.418$, verbal prompt $\kappa=0.676)$. After discussion of discrepancies, we agreed to code only veridical terms as correct (even if given with other terms), unrelated food types and qualitative responses as incorrect rather than far miss, onion as near miss for garlic, and /mint as correct for peppermint. After recording, coders were in perfect agreement $(\kappa=1)$.

\section{Field study}

For the field study (n=29), we used social media (e.g., Twitter, meetup.com), blogs (smellofevolution.com), word of mouth, and direct solicitation for participants. Testing was conducted on two separate days with two groups per day (10am and $2 \mathrm{pm})$. We used the area by the Tate Turbine Hall as a low odor control (low pollution, no food vendors, leafy area) for comparison to Southwark Bridge pedestrian area (traffic pollution, urine, cigarettes, and some food odors) and Borough Market (raw and cooked food vendors). We expected pollution to lower scores at Southwark and the odor signal to odor noise ratio at Borough to lower scores. The logistic regression indicates no significant effect from location (Table 1). A visualization change in the proportional odds (e.g., probability of being poor versus normal if you are indeterminate) show the opposite trend to what was expected. The odds of being 'poor' and 'indeterminate' decrease from Tate to the other locations (1=Tate, 2=Southwark, 3=Borough) while the odds of being 'normal' increase (Figure 1).

Table 1: Ordinal regression results

$\begin{array}{rrrrrrrrr} & \text { AIC } & \begin{array}{l}\text { Within } \\ \text { Subjects } \\ \text { Var }\end{array} & \begin{array}{l}\text { Between } \\ \text { Subjects }\end{array} & \text { Est } & \begin{array}{r}\text { Std } \\ \text { Err }\end{array} & \text { z } & \text { p } & \text { Odds Ratio } \\ \text { Field } & 126.45 & 6.51 & \text { Southwark } & 0.782 & 0.447 & 1.750 & 0.080 & 2.187\end{array}$




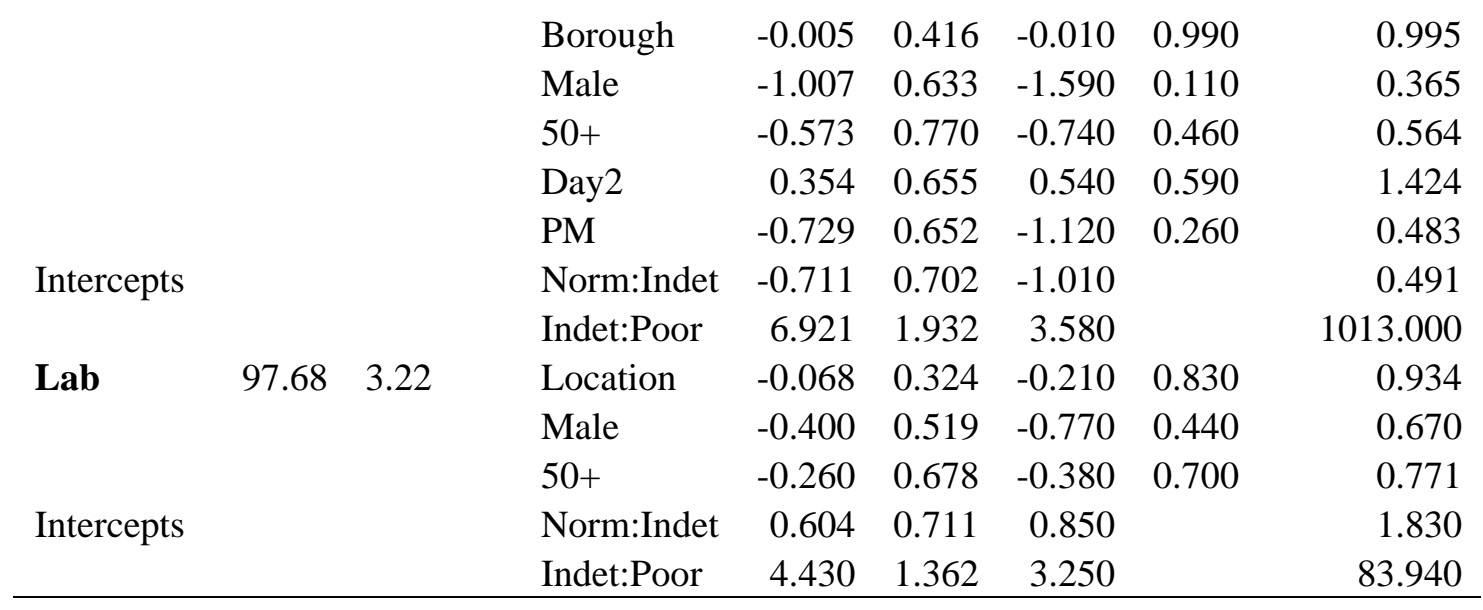

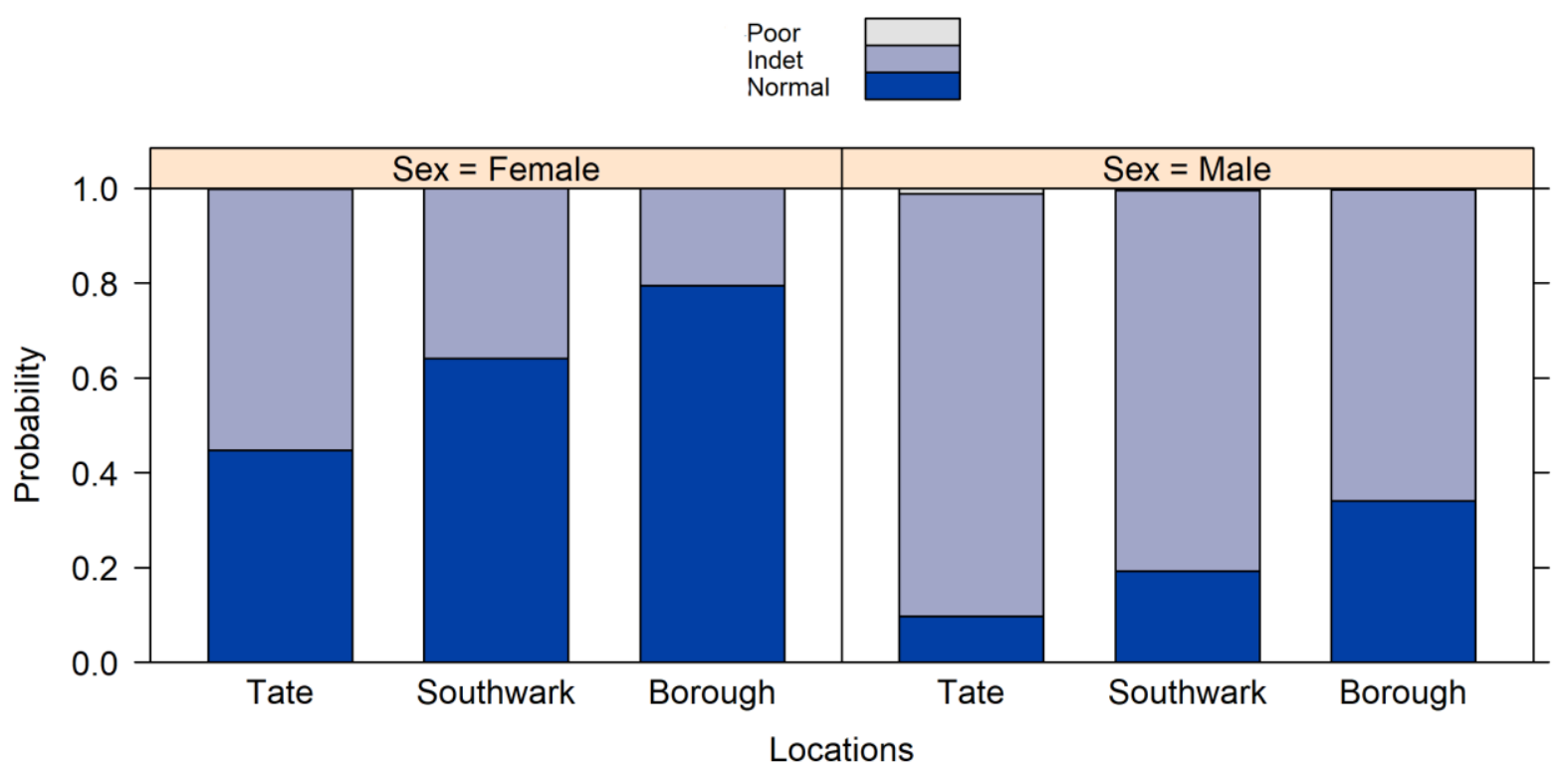

\section{Figure 1: Odds of change in olfactory ability in the field}

The only significant fixed effect is within-subjects. The difference between a model with and without the within-subjects term is significant (Likelihood Ratio statistic $=16.6, \mathrm{df}=1$, pvalue $=0.000045$ ). Most individuals vary from the sample average predicted response (set to 0 ) taking into account the estimated impact from fixed effects (Figure 2). While the significant random term in the regression indicates that individual variation impacts the model, it does not indicate if individuals vary in their scores across locations. Since there are no confounding factors from fixed effects, we used a paired ranks test to determine if there were significant changes in olfactory ability by individual (Table 2). There were no significant changes by individual for olfactory ability but there are two findings worth noting. First, the environmental impact on male olfactory ability is variable with some improving and some declining. So, while the summary statistics suggest no change, within-subjects change is taking place. Second, the environmental impact on female olfactory ability is consistent - all females improve at Borough (a dynamic food odor environment). 


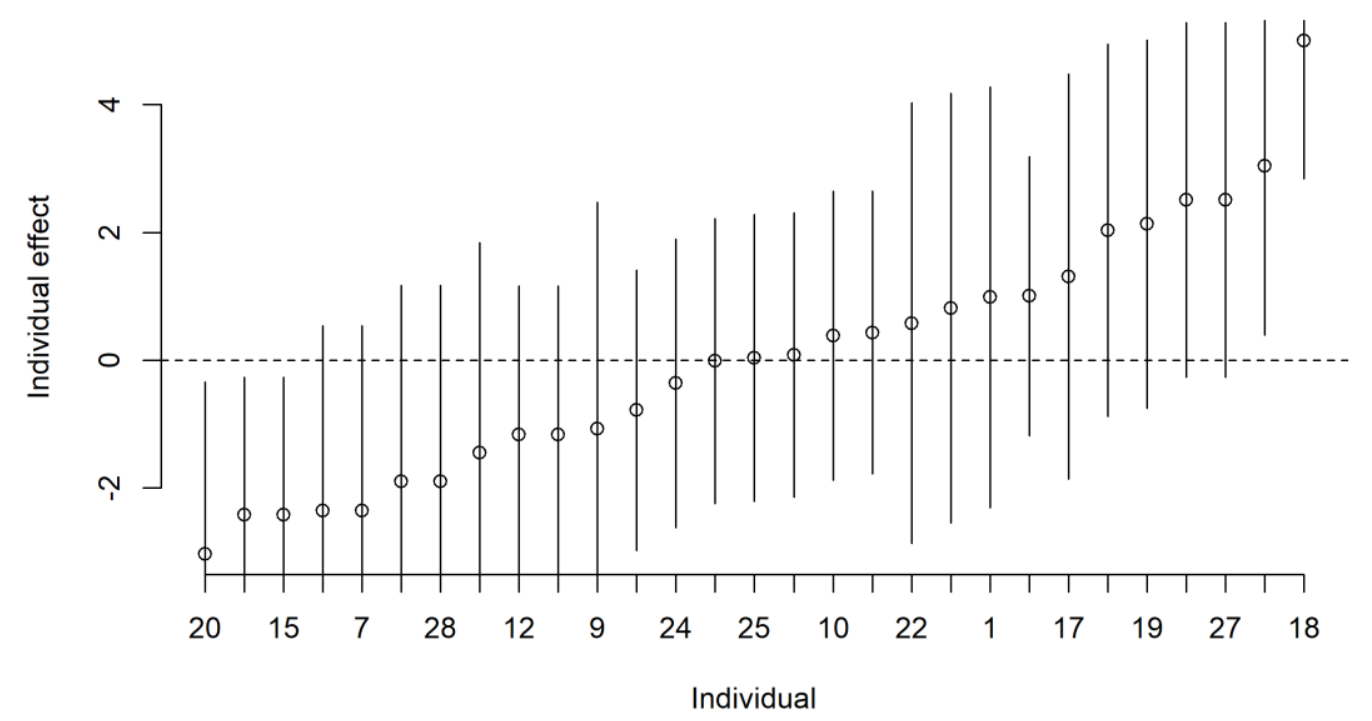

Figure 2: Random effect on olfactory ability (conditional modes with $95 \%$ confidence intervals based on individual variance), field study

Table 2: Sign Test Results

\begin{tabular}{lllrrr}
\hline Subset & Contrast & S & p-value & \multicolumn{2}{c}{ 95\% CI } \\
& & & & Lower & Upper \\
All & Tate:Borough & 3 & 0.100 & 0.857 & 0.951 \\
Female & Tate:Borough & 0 & 0.060 & 0.854 & 0.961 \\
Male & Tate:Borough & 3 & 1.000 & 0.854 & 0.961 \\
All & Tate:Southwark & 3 & 0.500 & 0.901 & 0.957 \\
Female & Tate:Southwark & 0 & 0.100 & 0.922 & 0.973 \\
Male & Tate:Southwark & 3 & 1.000 & 0.820 & 0.961 \\
All & Control:Experimental & 6 & 1.000 & 0.939 & 0.976 \\
Female & Control:Experimental & 5 & 0.700 & 0.939 & 0.976 \\
Male & Control:Experimental & 1 & 1.000 & 0.857 & 0.951 \\
\hline
\end{tabular}

\section{Lab Study}

For Repeat Labs $(n=30)$, we recruited University of Roehampton students and staff to participate in a lab-based experiment. Testing was conducted in two labs at the same time each day over three days. Olfactory ability in a control lab (well-ventilated low-odor) were compared to those taken in an experimental condition (food market odors). Odors (garlic, coffee, madras curry paste, and caramel furanone [3\% concentration]) were diffused each day one hour prior to testing. We expected olfactory ability to be negatively impacted by the experimental condition but this was not the case (Table 1). The odds of dropping in olfactory ability rank (Figure 3) under experimental conditions is consistent across but slight and not significant. 


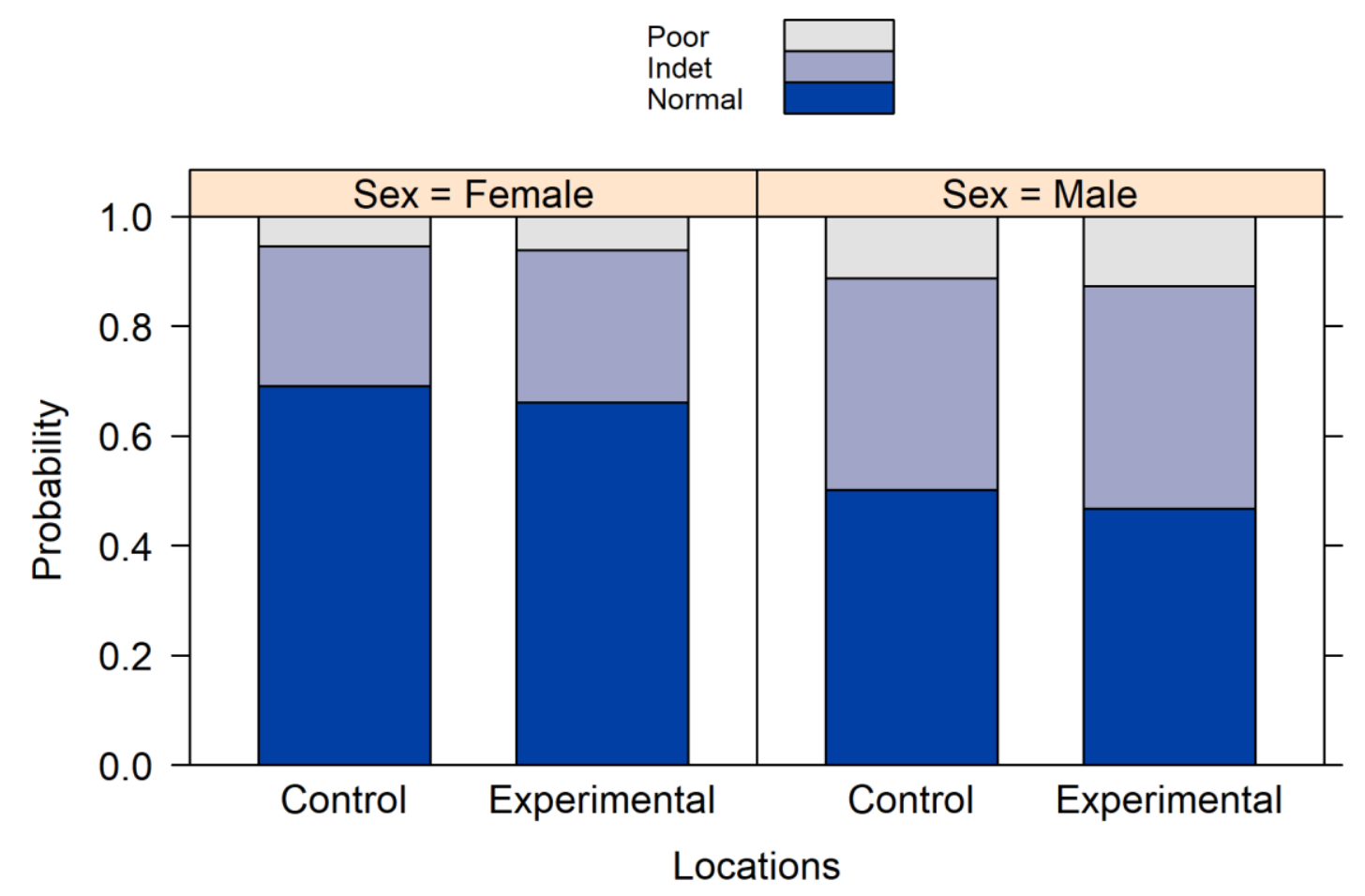

Figure 3: Odds of change in olfactory ability in the lab

Again, the only significant model term is within-subjects. The difference between a model with and without the within-subjects term is significant (Likelihood Ratio statistic $=3.74, \mathrm{df}=1, \mathrm{p}$ value $=0.053$. All individuals differ from the average predicted response to varying degrees. The paired ranks test did not return a significant result but the direction of change is variable across the sexes - while females tend to improve more than decline, the positive directionality of the the field study is not replicated. 


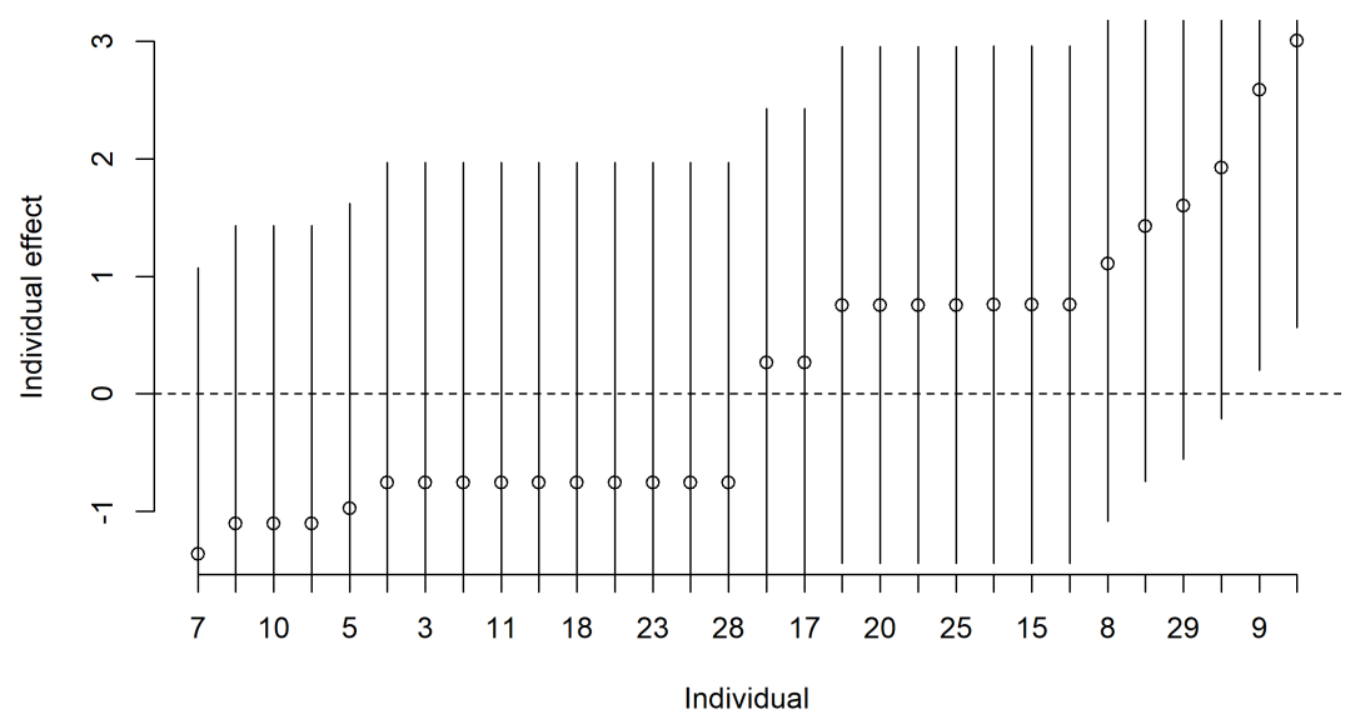

Figure 4: Random effect on olfactory ability (conditional modes with $95 \%$ confidence intervals based on individual variance), lab study

Despite the lack of significant differences among locations, the overall trend is that the control lab provided the best environment for olfactory ability (Figure 4). In addition, females consistently outperformed males with median and modal scores of 3 (normal) compared to male median and modal scores of 2 (indeterminate). Females captured a proportionately larger share of the normosmic diagnosis: $38 \%$ of results across trials were female and normosmic but only $14 \%$ were male and normosmic. While the field settings have a much lower probability of normosmia, females have a higher probability of normosmia and a very low probability of anosmia, compared to males.
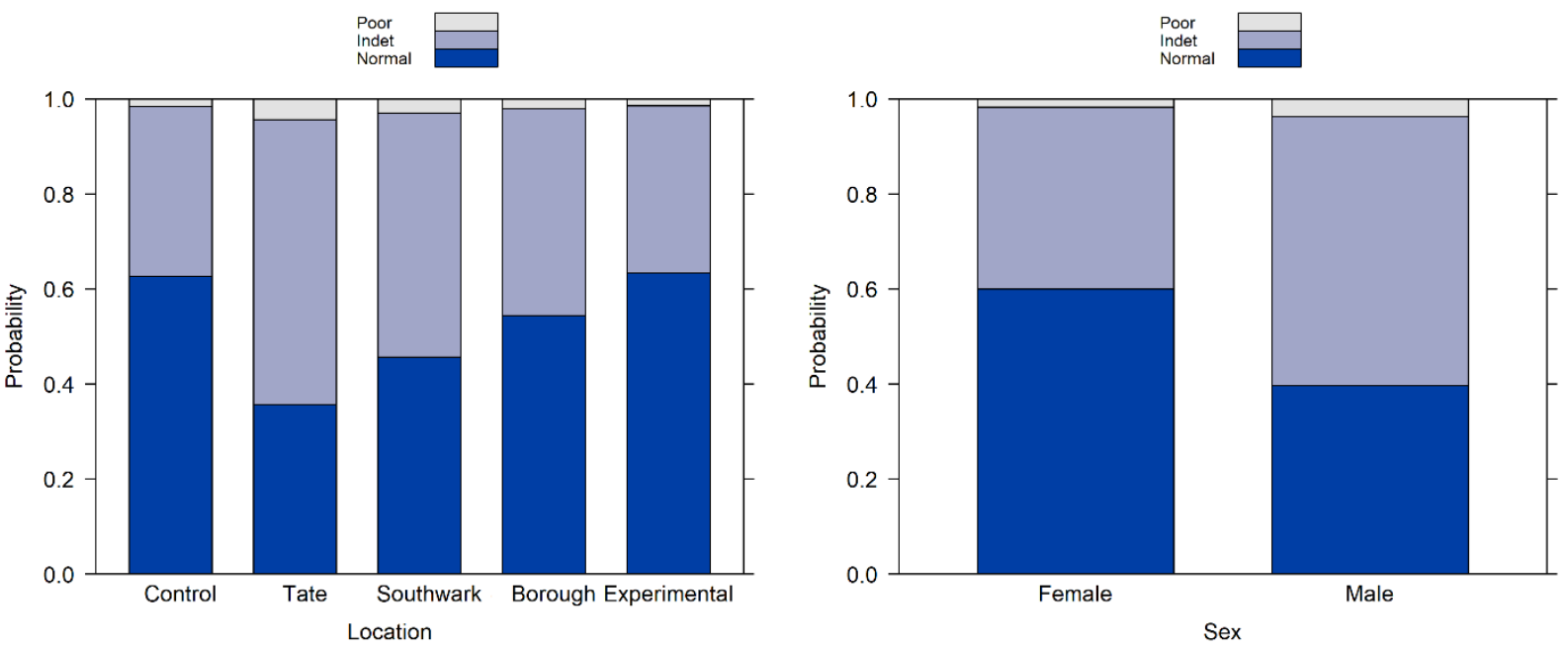

Figure 5: Proportional odds of change in olfactory ability by location and sex 


\section{DISCUSSION}

Our first research goal was to identify a utilitarian data collection method for olfactory ability in diverse non-lab environments. There is no tool for mobile rapid collection of olfactory ability. We had hoped that the five-item odor identification test might provide a rough measure but there are methodological problems with the tool that might affect outcomes. First, we found that participants were learning - they relied on verbal prompt terms after the first test, even when incorrect (choosing raspberry for orange consistently) and ignored the card in subsequent tests ('same as before but stronger', 'same as last time'). Learning will take place so perhaps longer between-test gaps would mitigate the effect but would require greater participant commitment to the process. Second, there is subjectivity introduced by observer coding of odor terms. Prior data on social consensus for odor terms and usage frequency of those terms would help mitigate marking correct choices as incorrect — such as knowing that a population associates the eugenol with the dentist, rose or lemon with cleaning supplies, or peppermint and orange with chewing gum. Another option is to code based on how consistent an individual is in odor term labels (Rabin and Cain 1984) but being consistent is not the same as correctly identifying an odor.

Our second research goal was to conduct preliminary data collection on how humans smell in the dynamic odorscapes of everyday living. Published data on olfactory ability differences in the lab compared to the field indicated a large effect size (Sorokowska et al. 2015; Sorokowska et al. 2014; Sorokowska et al. 2013), which suggested our sample size in a repeated measures design was sufficient. We believe that the environmental effect size is smaller than estimated when comparing the same populations in a repeated measures approach. Despite the statistically null result, the data visualization reveals that olfactory ability was best in the lab and that comparing lab-based data to field-based data is problematic.

While collecting data in the field (i.e., non-lab settings) may seem superfluous to those accustomed to lab environments, the clinically-derived dataset is insufficient to capture variation in and the breadth and context of human olfaction. Field-based data collection methods are needed to widen participation beyond current olfactory ability datasets that are comprised of non-representative samples. Why non-representative? First, WEIRD samples are biased by individuals who can afford the costs of travel and time to be tested in a lab. Second, WEIRD populations (or even simply EIRD) are a global minority. Third, many populations are geographically isolated from lab-testing sites - this describes the majority of indigenous, traditionally living, small-scale societies. Fourth, lab conditions cannot be recreated in the field. Clinical data serve their purposes but field data are needed to address an entirely different question: are meaningful biological differences in olfactory ability explained by ecological context?

The overabundance of human olfactory sensory neurons dedicated to food-related odors indicates these odors have particular evolutionary and ecological salience (Saraiva et al. 2019). Data from hunter-gatherers suggest that foraging activity may have placed females under a separate selection regime than males and olfactory ability may have been part of that package. While most animal-based food derives from both male and female labor, the majority of the plant-based food derives from female labor (Marlowe 2007; Waguespack 2005) and constitutes roughly one third of total energy intake in most hunter-gatherer populations (Ströhle and Hahn 
2011). A stronger ability to remember and distinguish among food odors would be useful in plant-based foraging but not useful in hunting which requires visual and tracking skills. Women outperform men at foraging tasks that involve spatial memory and navigation skills (McBurney et al. 1997; New et al. 2007). An ability to map food resources and navigate a catchment area would be useful in food foraging but not important when following prey. Females also more frequently use tools for food foraging and processing, a trait shared with our closest relatives, chimps and bonobos (Gruber et al. 2010; Pruetz et al. 2015), which suggests the selective pressure acting on females predates the Homo-Pan split. There is ample evidence in biological structures that females share a pattern unique to their sex - females have roughly double the number of olfactory bulb cells, both glial cells and neurons (Oliveira-Pinto et al. 2014). There is ample evidence in cognitive processing that females have a stronger olfactory modality than men. Even when accounting for different cultural settings in industrialized societies (Doty et al. 1985), women outperform men in smell testing (Dalton et al. 2002; Doty et al. 1985; Doty and Cameron 2009; Doty et al. 1984b; Oliveira-Pinto et al. 2014). Women are more interested than men in smell (Seo et al. 2010), are better than men at learning odors (Doty et al. 1984a; Ferdenzi et al. 2013; Larsson 1997; Larsson et al. 2003; Lehrner 1993), and more proficient than men at odor identification tasks (Oberg et al. 2002). Turning again to our closest relatives, female chimpanzees forage alone but in spaces that overlap with other females, which generates some competition to space and food resources. High-ranking females tend to have preferential access to resource-rich sites which correlates with greater reproductive success (Pusey and SchroepferWalker 2013). So, reproduction is, in part, determined by foraging ability. We would argue that females are more likely to have a better signal-to-noise ability when detecting food odors, an innate skill well-suited to successful foraging and group provision-such as seen in our data when female olfactory ability was enhanced in the rich food-odor environment of Borough Market.

In conclusion and despite published data indicating a significant environmental effect on olfactory ability (Sorokowska et al. 2014; Sorokowska et al. 2013), we failed to detect any significant differences in two repeated measures studies. We suspect that either withinpopulation repeated measures tests have a more subtle impact from environment on olfactory ability than cross-cultural comparisons or that the comparison of field- to lab-collected data overemphasized differences. We also found that odor identification is a less than ideal tool for assessing olfactory ability despite ease of delivery and speedy test time. We argue that fieldbased methods are needed to characterize representative variation in human olfactory ability and the importance of ecological context. Lastly, we find that even in the field and despite methodological problems, females still exhibit better olfactory ability and that may be an artifact of long-standing evolutionary pressure acting on a mosaic of traits related to food foraging in females only. 
bioRxiv preprint doi: https://doi.org/10.1101/270744; this version posted August 21,2019 . The copyright holder for this preprint (which was not certified by peer review) is the author/funder, who has granted bioRxiv a license to display the preprint in perpetuity. It is made available under aCC-BY-NC-ND 4.0 International license.

\section{CONFLICT OF INTERESTS}

There are no conflicts of interest.

\section{FUNDING}

None

\section{ACKNOWLEDGEMENTS}

Roehampton University staff and students for their support. 


\section{REFERENCES}

Auffarth B. 2013. Understanding smell-The olfactory stimulus problem. Neurosci. Biobehav. Rev. 37: 1667-1679.

Barkat S, Le Berre E, Coureaud G, Sicard G, Thomas-Danguin T. 2012. Perceptual blending in odor mixtures depends on the nature of odorants and human olfactory expertise. Chem. Senses 37: 159-166.

Berkelaar M. 2015. lpSolve: Interface to 'Lp_solve' v. 5.5 to Solve Linear/Integer Programs. R package version 5.6.13. https://CRAN.R-project.org/package=lpSolve.

Cain W. 1979. To know with the nose: keys to odor identification. Science 203: 467-470.

Charif D, Lobry JR. 2007. 1.0-2: a contributed package to the $\{\mathrm{R}\}$ project for statistical computing devoted to biological sequences retrieval and analysis. In: Bastolla U, Porto M, H.E. Roman HE, Vendruscolo M, (eds.), Structural approaches to sequence evolution: Molecules, networks, populations. New York: Springer Verlag. p. 207-232.

Christensen RHB. 2019. ordinal - Regression Models for Ordinal Data. R package version 2019.3-9. http://www.cran.r-project.org/package=ordinal/.

Dalton P. 2000. Psychophysical and behavioral characteristics of olfactory adaptation. Chem. Senses 25: 487-492.

Dalton P, Doolittle N, Breslin PAS. 2002. Gender-specific induction of enhanced sensitivity to odors. Nat. Neurosci. 5: 199-200.

Doty R, Shaman P, Applebaum S, Giberson R, Siksorski L, Rosenberg L. 1984a. Smell identification ability: changes with age. Science 226: 1441-1443.

Doty RL, Applebaum S, Zusho H, Settle RG. 1985. Sex differences in odor identification ability: A cross-cultural analysis. Neuropsychologia 23: 667-672.

Doty RL, Cameron EL. 2009. Sex differences and reproductive hormone influences on human odor perception. Physiol. Behav. 97: 213-228.

Doty RL, Shaman P, Applebaum SL, Giberson R, Siksorski L, Rosenberg L. 1984b. Smell identification ability: changes with age. Science 226.

Ferdenzi C, Roberts SC, Schirmer A, Delplanque S, Cekic S, Porcherot C, Cayeux I, Sander D, Grandjean D. 2013. Variability of affective responses to odors: culture, gender, and olfactory knowledge. Chem. Senses 38: 175-186.

Fox J, Hong J. 2009. Effect Displays in R for Multinomial and Proportional-Odds Logit Models: Extensions to the effects Package. 2009 32: 24.

Gamer M, Lemon J, Fellows I, Singh P. 2012. irr: Various Coefficients of Interrater Reliability and Agreement. R package version 0.84. https://CRAN.R-project.org/package=irr.

Gruber T, Clay Z, Zuberbühler K. 2010. A comparison of bonobo and chimpanzee tool use: evidence for a female bias in the Pan lineage. Anim. Behav. 80: 1023-1033. Hanel PHP, Vione KC. 2016. Do Student Samples Provide an Accurate Estimate of the General Public? PLoS One 11: e0168354.

Henrich J, Heine SJ, Norenzayan A. 2010. Most people are not WEIRD. Nature 466: 29.

Hummel T, Olgun S, Gerber J, Huchel U, Frasnelli J. 2013. Brain responses to odor mixtures with sub-threshold components. Front. Psychol. 4: 786.

Hummel T, Pfetzing U, Lötsch J. 2010. A short olfactory test based on the identification of three odors. J. Neurol. 257: 1316-1321.

Jackman AH, Doty RL. 2005. Utility of a three-item smell identification test in detecting olfactory dysfunction. Laryngoscope 115: 2209-2212. 
Jinks A, Laing DG. 1999. A limit in the processing of components in odour mixtures. Perception 28: 395-404.

Kern DW, Wroblewski KE, Schumm LP, Pinto JM, McClintock MK. 2014. Field Survey Measures of Olfaction:The Olfactory Function Field Exam (OFFE). Field Methods 26: 421-434. Larsson M. 1997. Semantic Factors in Episodic Recognition of Common Odors in Early and Late Adulthood: a Review. Chem. Senses 22: 623-633.

Larsson M, Lövdén M, Nilsson L-G. 2003. Sex differences in recollective experience for olfactory and verbal information. Acta Psychol. (Amst.) 112: 89-103.

Lehrner JP. 1993. Gender differences in long-term odor recognition memory: verbal versus sensory influences and the consistency of label use. Chem. Senses 18: 17-26.

Marlowe FW. 2007. Hunting and Gathering: The Human Sexual Division of Foraging Labor. Cross-Cultural Research 41: 170-195.

Martinez B, Karunanayaka P, Wang J, Tobia MJ, Vasavada M, Eslinger PJ, Yang QX. 2017. Different patterns of age-related central olfactory decline in men and women as quantified by olfactory fMRI. Oncotarget 8: 79212-79222.

McBurney DH, Gaulin SJC, Devineni T, Adams C. 1997. Superior spatial memory of women: Stronger evidence for the gathering hypothesis. Evolution and Human Behavior 18: 165-174. McCullagh P. 1980. Regression Models for Ordinal Data. Journal of the Royal Statistical Society. Series B (Methodological) 42: 109-142.

Morquecho-Campos P, Larsson M, Boesveldt S, Olofsson JK. 2019. Achieving Olfactory Expertise: Training for Transfer in Odor Identification. Chem. Senses 44: 197-203.

Mueller C, Renner B. 2006. A new procedure for the short screening of olfactory function using five items from the "Sniffin' Sticks" identification test kit. American Journal of Rhinology and Allergy 20: 113-116.

Neumann C, Tsioulos K, Merkonidis C, Salam M, Clark A, Philpott C. 2012. Validation study of the 'Sniffin' Sticks' olfactory test in a British population: a preliminary communication. Clin. Otolaryngol. 37: 23-27.

New J, Krasnow Max M, Truxaw D, Gaulin Steven JC. 2007. Spatial adaptations for plant foraging: women excel and calories count. Proceedings of the Royal Society B: Biological Sciences 274: 2679-2684.

Oberg C, Larsson M, Backman L. 2002. Differential sex effects in olfactory functioning: the role of verbal processing. J. Int. Neuropsychol. Soc. 8: 691-698.

Oliveira-Pinto AV, Santos RM, Coutinho RA, Oliveira LM, Santos GB, Alho ATL, Leite REP, Farfel JM, Suemoto CK, Grinberg LT, Pasqualucci CA, Jacob-Filho W, Lent R. 2014. Sexual dimorphism in the human olfactory bulb: females have more neurons and glial cells than males. PLoS One 9: e111733.

Pruetz JD, Bertolani P, Ontl KB, Lindshield S, Shelley M, Wessling EG. 2015. New evidence on the tool-assisted hunting exhibited by chimpanzees (Pan troglodytes verus) in a savannah habitat at Fongoli, Sénégal. Royal Society Open Science 2: 140507.

Pusey AE, Schroepfer-Walker K. 2013. Female competition in chimpanzees. Philosophical transactions of the Royal Society of London. Series B, Biological sciences 368: 2013007720130077.

Rabin MD, Cain WS. 1984. Odor recognition: Familiarity, identifiability, and encoding consistency. J. Exp. Psychol. Learn. Mem. Cogn. 10: 316-325.

RStudio Team. 2015. RStudio: Integrated Development for R. Boston, MA: RStudio, Inc. 
Saraiva LR, Riveros-McKay F, Mezzavilla M, Abou-Moussa EH, Arayata CJ, Makhlouf M, Trimmer C, Ibarra-Soria X, Khan M, Van Gerven L, Jorissen M, Gibbs M, O’Flynn C, McGrane S, Mombaerts P, Marioni JC, Mainland JD, Logan DW. 2019. A transcriptomic atlas of mammalian olfactory mucosae reveals an evolutionary influence on food odor detection in humans. Science Advances 5: eaax0396.

Seo H-S, Guarneros M, Hudson R, Distel H, Min B-C, Kang J-K, Croy I, Vodicka J, Hummel T. 2010. Attitudes toward Olfaction: A Cross-regional Study. Chem. Senses 36: 177-187.

Sinding C, Coureaud G, Bervialle B, Martin C, Schaal B, Thomas-Danguin T. 2015. Experience shapes our odor perception but depends on the initial perceptual processing of the stimulus. Attention, perception \& psychophysics 77: 1794-1806.

Sinding C, Puschmann L, Hummel T. 2014. Is the Age-Related Loss in Olfactory Sensitivity Similar for Light and Heavy Molecules? Chem. Senses 39: 383-390.

Sorokowska A, Sorokowski P, Frackowiak T. 2015. Determinants of human olfactory performance: A cross-cultural study. Sci. Total Environ. 506-507: 196-200.

Sorokowska A, Sorokowski P, Hummel T. 2014. Cross-cultural administration of an odor discrimination test. Chemosensory Perception 7: 85-90.

Sorokowska A, Sorokowski P, Hummel T, Huanca T. 2013. Olfaction and environment: Tsimane' of Bolivian rainforest have lower threshold of odor detection than industrialized German people. PLoS One 8: e69203.

Sorokowski P, Karwowski M, Misiak M, Marczak MK, Dziekan M, Hummel T, Sorokowska A. 2019. Sex Differences in Human Olfaction: A Meta-Analysis. Front. Psychol. 10.

Ströhle A, Hahn A. 2011. Diets of modern hunter-gatherers vary substantially in their carbohydrate content depending on ecoenvironments: results from an ethnographic analysis. Nutr. Res. 31: 429-435.

Venables WN, Ripley BD. 2002. Modern Applied Statistics with S. New York: Springer. Waguespack N. 2005. The organization of male and female labor in foraging societies: Implications for early Paleoindian archaeology. American Anthropologist 107: 666-676. Weiss T, Snitz K, Yablonka A, Khan RM, Gafsou D, Schneidman E, Sobel N. 2012. Perceptual convergence of multi-component mixtures in olfaction implies an olfactory white. Proc. Natl. Acad. Sci. U. S. A. 109: 19959-19964. 